\title{
Wine Polyphenols: Potential Agents in Neuroprotection
}

\author{
Abdelkader Basli, ${ }^{1,2}$ Stéphanie Soulet, ${ }^{3}$ Nassima Chaher, ${ }^{4}$ Jean-Michel Mérillon, ${ }^{1}$ \\ Mohamed Chibane, ${ }^{5}$ Jean-Pierre Monti, ${ }^{1}$ and Tristan Richard ${ }^{1}$ \\ ${ }^{1}$ GESVAB, EA 3675, ISVV, Université de Bordeaux, 33882 Villenave d'Ornon, France \\ ${ }^{2}$ Laboratoire 3BS, Université de Bejaia, Targa Ouzemour, 06000 Béjaia, Algeria \\ ${ }^{3}$ BIOTEM, EA 4239, Université de la Polynésie Française, BP 6570, Tahiti, 98702 FAAA, Polynésie Française, France \\ ${ }^{4}$ Laboratoire de Biochimie Appliquée, Faculté des Sciences de la Nature et de la vie, Université de Bejaia, 06000 Béjaia, Algeria \\ ${ }^{5}$ Laboratoire de Technologie Alimentaire, Faculté des Sciences, Université AMO Bouira, Bouira, Algeria
}

Correspondence should be addressed to Tristan Richard, trichard33@gmail.com

Received 10 February 2012; Revised 20 April 2012; Accepted 20 April 2012

Academic Editor: David Vauzour

Copyright ( $) 2012$ Abdelkader Basli et al. This is an open access article distributed under the Creative Commons Attribution License, which permits unrestricted use, distribution, and reproduction in any medium, provided the original work is properly cited.

\begin{abstract}
There are numerous studies indicating that a moderate consumption of red wine provides certain health benefits, such as the protection against neurodegenerative diseases. This protective effect is most likely due to the presence of phenolic compounds in wine. Wine polyphenolic compounds are well known for the antioxidant properties. Oxidative stress is involved in many forms of cellular and molecular deterioration. This damage can lead to cell death and various neurodegenerative disorders, such as Parkinson's or Alzheimer's diseases. Extensive investigations have been undertaken to determine the neuroprotective effects of wine-related polyphenols. In this review we present the neuroprotective abilities of the major classes of wine-related polyphenols.
\end{abstract}

\section{Introduction}

Aging is a risk factor common to a number of neurodegenerative diseases, including Alzheimer's disease $(\mathrm{AD})$ and Parkinson's disease. Moreover, associated with the population aging, the occurrence of these neurodegenerative disorders is also likely to augment [1]. In addition to the possible involvement in aging, the common characteristic of most degenerative diseases is that they result from neuronal death. Oxidative stress may play a crucial role in progressive neuronal death [2].

Free radicals are oxidative molecules that occur naturally in the environment but can also be generated in vivo. Reactive oxygen species (ROS) are produced by immune cells in order to sustain their antibacterial and antifungal functions [3]. When ROS are overproduced, they are taken in charge by various enzymatic pathways for inactivation (superoxide dismutase, catalase, cytochromes, etc.) [4, 5]. Although these enzymatic pathways can be overstepped, ROS accumulate and can react with the different cell molecules such as lipids, proteins, carbohydrates, and nucleic acids. These interactions with the ROS apply an oxidative stress to cells [6]. Some tissues, particularly the brain, are highly exposed to oxidative damages because of their elevated oxygen consumption and the induced generation of large amounts of reactive oxygen species $[7,8]$.

Oxidative stress resulting in ROS generation and inflammation is responsible for many forms of cellular and molecular deterioration such as mitochondrial collapsing, DNA damage, and protein, carbohydrate, and lipid oxidation [9]. This damage can lead to early cell aging, cell death, and various chronic pathologies like neurodegenerative disorders, cardiovascular illnesses, cancers, or type 2 diabetes $[2,6,10,11]$. Difficulty in treating these diseases and better understanding of their development and causes highlight the usefulness of antioxidants as prevention treatments.

A number of epidemiological studies have shown that the consumption of a diet rich in antioxidants can influence the incidence of neurodegenerative disorders [12]. Orgogozo et al. have shown a positive correlation between a moderate consumption of red wine and a decreased incidence of dementia $[13,14]$. This protective effect is most likely due to the presence of phenolic compounds in wine. Wine and grape vine polyphenols are mainly flavonoids (flavanols, 
flavonols, and anthocyanins) and nonflavonoids (phenolic acids, hydrolysable tannins, and stilbenes) [15]. Extensive investigations have been undertaken to determine the neuroprotective effects of wine polyphenols [16-19]. These polyphenols have displayed neuroprotective capacities in numerous in vitro and animal models of neurotoxicities [19]. Several neuroprotective mechanisms of action have been proposed, suggesting that polyphenols exert their activities by reducing the production and the accumulation of ROS, whose accumulation is likely to play a crucial pathological role in brain aging, reducing oxidative stress and inflammation and modulating the activity of intracellular signal transduction molecules [19-21].

In this review we investigate the neuroprotective abilities of the major classes of polyphenols in wine: flavanols, proanthocyanins, flavonols, anthocyanins, phenolic acids, tannins, and stilbenes. Each specific class of polyphenol has shown neuroprotective effects against neurodegenerative diseases. Their neuroprotective activity has been documented, and we underline the evidence suggesting that their mechanism of action involves their antioxidant activity.

\section{Wine Polyphenols}

Products such as wine extract, grape seed, and grape skin extracts are all known to contain a large variety of potent antioxidants in the form of polyphenols. Plant phenolic constituents are produced through two metabolic pathways, the main being that of shikimic acid which leads to cinnamic acids, whereas the polyacetate pathway induces the linkage of a second aromatic ring to the first pathway molecules [2224].

Wines contain various water-soluble polyphenols including phenolic acids, stilbenes, tannins, flavanols, flavonols, and anthocyanins (see Figure 1). Wine phenolics are divided into two groups: flavonoid and nonflavonoid. The amounts of phenolic compounds in wines are highly variable due to varietal differences and process diversities. Indicative levels of phenolic components in wine are shown in Table 1 [15]. Due to wine processing, red wines contain more polyphenols than white wines. Red wine has more antioxidant capacity than white wine due to its phenolic content [25-27]. Phenolic red wines are mainly composed by flavonoids with $1450 \mathrm{mg} / \mathrm{L}$ for young wines and $1285 \mathrm{mg} / \mathrm{L}$ for aged ones. Phenolic white wines are composed principally of nonflavonoids with $164 \mathrm{mg} / \mathrm{L}$ for young wines and $245 \mathrm{mg} / \mathrm{L}$ for aged ones [15, 24].

\section{Wine Polyphenols and Neuroprotection}

\subsection{Flavonoids and Neuroprotection}

3.1.1. Flavanols. The flavanols, also called flavan-3-ols or catechins, are the most reduced form of flavonoids. They are present in various plants and are associated with the health benefits of green tea $[28,29]$. The levels in wine depend on the different grape cultivars and are typically in the range of $20-100 \mathrm{mg} / \mathrm{L}$. Catechin is usually the major flavanol in wine
$[15,30]$. The condensations of flavanol in wine induce the formation of oligomers (proanthocyanidins and condensed tannins).

Flavanol intake has been associated with various beneficial health effects $[31,32]$, and flavanols are known to be brain-permeable substances [33]. Their transport is stereoselective involving one or more stereoselective entities and metabolizing with glucuronic acid, for example [34]. Numerous studies indicate that flavanols are of benefit for neuronal health. Catechin may protect against the brain injuries produced by endogenous neurotoxins involved in the onset of Parkinson's disease [35]. Catechin and epicatechin gallate have also shown an ability to suppress neuroinflammation and can attenuate and inhibit activation of microglia and/or astrocytes associated with the release of the mediators linked to the apoptotic death of neurons [36]. In addition, numerous studies indicate that catechin derivatives may delay the onset of neurodegenerative disorders such as Alzheimer's disease through a numerous different mechanisms such as iron chelators, radical scavengers, and modulators of prosurvival genes [31, 37-40].

3.1.2. Proanthocyanidins. Proanthocyanidins and condensed tannins are complex flavonoid polymers naturally present in cereals, legumes, and fruits [41]. They are mainly formed by the condensation of flavanol units to generate oligomers (proanthocyanidins) and polymers (condensed tannins). Their levels in wine depend on pressing techniques and grape varieties. Typically they range from $5 \mathrm{mg} / \mathrm{L}$ in white wines to $1 \mathrm{~g} / \mathrm{L}$ or even higher levels in old red wines $[15,41]$. They are associated with a change in wine quality such as a modification of the hue and a decrease in astringency.

Very few studies have concerned the bioavailability of proanthocyanidins. Condensed tannins should be degraded in monomeric phenols, absorbed and metabolized, as has been shown for other flavonoids $[1,2]$. Numerous studies indicate that proanthocyanidins and condensed tannins might prevent both cancers and cardiovascular diseases [42, 43]. Some reports demonstrate that its biological abilities to scavenge the reactive oxygen species are associated to the degree of polyphenol oligomerization. Some of these polyphenols might have specific structures that exhibit neuroprotective effects by interacting with putative neuronspecific receptors [44]. Takahashi et al. have shown that procyanidin oligomers from grape seed exhibit higher growthpromoting activity than the monomers toward mouse hair epithelial cells in vitro and in vivo, these results indicating that the specific effect might be correlated with their structure [45]. Other research on rat brain suggests that grape seed extract enriched in proanthocyanidins might protect against pathology age-related oxidative brain damage [46].

3.1.3. Flavonols. Flavonols occur in a wide range of vegetables. There polyphenols are always found in glycoside forms in plants including grape berries, where they are present in the skin. Flavonol glycosides and aglycones are found in grape wine from trace amounts up to $200 \mathrm{mg} / \mathrm{L}$ in some 


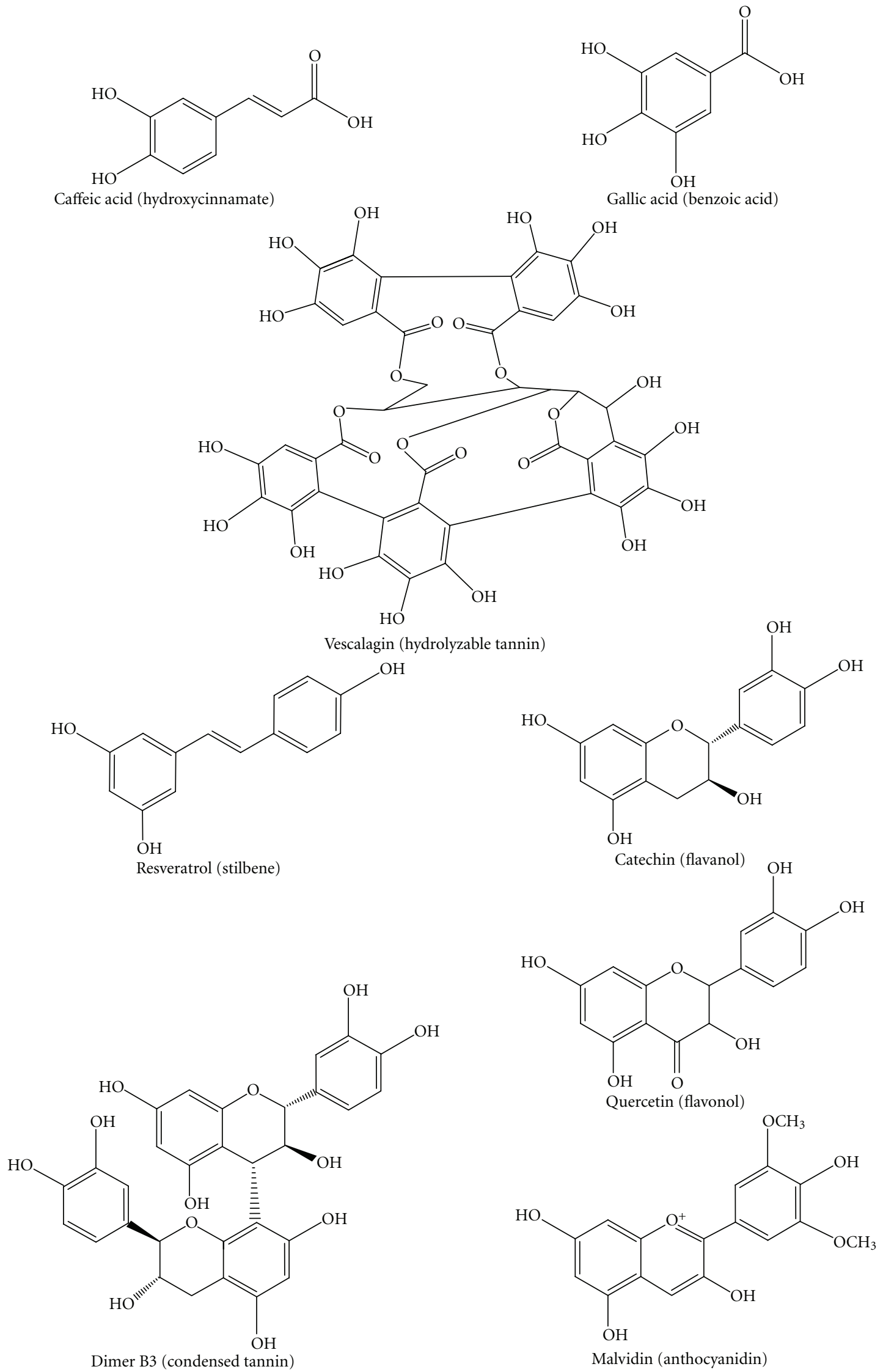

FIgURE 1: Chemical structures of some phenolic compounds from wine. 
TABLE 1: The levels of principal phenolic classes $(\mathrm{mg} / \mathrm{L})$ in red and white table wine [15].

\begin{tabular}{lcccc}
\hline \multirow{2}{*}{ Phenol class } & \multicolumn{2}{c}{ White wine } & \multicolumn{2}{c}{ Red wine } \\
& Young & Aged & Young & Aged \\
\hline nonflavonoids & & & & \\
hydroxycinnamates & 154 & 130 & 165 & 60 \\
benzoic acids & 10 & 15 & 60 & 60 \\
hydrolyzable tannins & 0 & 100 & 0 & 250 \\
stilbenes (resveratrol) & 0.5 & 0.5 & 7 & 7 \\
\hline Total mg/L & 164.5 & 245.5 & 232 & 377 \\
\hline flavonoids & & & & \\
flavanol monomers & 25 & 15 & 200 & 100 \\
Condensed tannins & 20 & 25 & 750 & 1000 \\
flavonols & - & - & 100 & 100 \\
anthocyanins & - & - & 400 & 90 \\
\hline Total mg/L & 45 & 40 & 1450 & 1285 \\
\hline
\end{tabular}

red wines [15, 47, 48]. Myricetin, quercetin, and kaempferol conjugates are the major flavonols in wine [48, 49].

Primary results indicate that flavonols can pass the blood-brain barrier [50, 51]. Moreover, numerous studies indicated that flavonols, in addition to many other health benefits, contribute significantly to the protection of neuronal cells against oxidative-stress-induced neurotoxicty $[52,53]$. In Alzheimer's disease, neuronal loss is preceded by the extracellular accumulation of amyloid- $\beta$ peptide $(A \beta)$. It has been shown that pretreatment of primary hippocampal cultures with quercetin significantly attenuates $\mathrm{A} \beta$-induced toxicity, lipid peroxidation, protein oxidation and apoptosis [54]. A dose-response study indicated that quercetin exhibited protective capacities against $\mathrm{A} \beta$-induced toxicity by modulating oxidative stress at lower doses [54]. In cerebral ischemia, calcium dysregulation is one of the main instigators of neuronal cell death and brain damage. Quercetin has been shown to exert significant protection against ischemic injury. Indeed, treatment with quercetin reduced the spectrin breakdown products caused by ischemic activation of calcium-dependent protease calpoin and inhibited the acid-mediated intracellular calcium level [55].

3.1.4. Anthocyanins. Anthocyanins act as guard systems in plants and protect them from UV damage. They form complex molecules with other phenolic molecules and strongly contribute to the color and the aging of wine [56-58]. The aglycone ring of these flavonoids is called anthocyanidin. However, nonconjugated anthocyanidins are never found in grapes or wine, except in trace quantities. In wine there are five anthocyanidins: malvidin, cyanidin, delphinidin, peonidin, and petunidin. Malvidin is the most abundant anthocyanidin in red wines [15].

Among the wine flavonoids, anthocyanins constitute one of the higher potent antioxidants correlated to their capacity to delocalize electrons and form resonating structures [5962 ]. Anthocyanins present numerous health benefits such as anticarcinogenic, anti-inflammatory, or antidiabetic effects
$[61,63-66]$. Anthocyanins also possess beneficial neuroprotective abilities. Some of them have the ability to cross the blood-brain barrier and diffuse through the central nervous system $[67,68]$. Anthocyanins have neuroprotective benefits in reducing age-associated oxidative stress and improving cognitive brain function $[61,69-72]$. They induce significant neuroprotective effects against oxidative stress, DNA fragmentation and lipid peroxidation in mouse brain $[73,74]$. Thus, it appears that the antioxidant and anti-inflammatory effects of anthocyanins contribute to its neuroprotective effect.

\subsection{Nonflavonoids and Neuroprotection [73, 74]}

3.2.1. Phenolic Acids. The benzoic acids are a minor component in wines. Whereas the hydroxycinnamates are the most important class of nonflavonoid phenols in grape vine and the major class of phenolics in white wine $[15,75]$. The three important ones in wine are coumaric acid, caffeic acid, and ferulic acid. Amount of total hydroxycinnamates in wine are typically about $60 \mathrm{mg} / \mathrm{L}$ in reds and $130 \mathrm{mg} / \mathrm{L}$ in whites [15].

Hydroxycinnamates have an antioxidant activity by scavenging free radicals $[76,77]$. Their strong antioxidant properties help to explain their beneficial role on health and in reducing disease risk. Hydroxycinnamates and other phenolic acids have received less attention. It has been shown that p-coumaric acid, hydroxycinnamates caffeic acid, and a Champagne wine extract rich in these compounds have neuroprotective effects against injury induced by 5 S-cysteinyl-dopamine in vitro [78]. Caffeic acid has been reported to have neuroprotective effects against $A \beta$-induced neurotoxicity in vitro and to inhibit peroxynitrite-induced neuronal injury [78-80]. Ferulic acid has been showed to protect primary neuronal cell cultures against hydroxyl- and peroxyl-radical-mediated oxidative damage $[81,82]$.

3.2.2. Hydrolyzable Tannins. Tannins are water-soluble polyphenols. One of the major properties of these molecules is their capacity to precipitate proteins such as gelatin from solution [83-85]. In wine, hydrolyzable tannins arise during maturation and ageing of wines in oak barrels [86]. Castalagin and vescalagine are the main representative compounds of ellagic tannins [87]. Their levels are about $100 \mathrm{mg} / \mathrm{L}$ in aged white wines, while red wine levels are about $250 \mathrm{mg} / \mathrm{L}$ after aging in oak barrels for two or more years $[15,88]$. They are mainly ellagic acid and gallic acid ester derivatives with glucose or other sugars. Due to the presence of the ester linkage, they are described as being hydrolyzable. Hydrolyzable tannins are not present in Vitis vinifera but are present in other fruits such as muscadine grapes and raspberries [89]. These polyphenols are excellentantioxidantsand natural preservatives, also helping give the wine structure and texture. However, recent research on tannins has focused on their potential to impact positively on human health. Tannins have demonstrated a host of potent biological activities, antiperoxidation properties, inhibition of mutagenicity of carcinogens and tumor promotion, specific antitumor abilities in relation with tannin structures, antibacterial activity, 
and antiviral activity [89-91]. In vivo, ellagitannins are mainly transformed into ellagic acid and its metabolites. In fact, they could be the agent responsible for the effects of dietary ellagitannins observed in vivo $[92,93]$.

There are few studies whose objective has been the neuroprotective activity of hydrolyzable tannins. Ellagic acid has been reported to promote the formation of $\beta$ A fibril and significant oligomer loss, in contradiction to previous results indicating that polyphenols inhibited $\mathrm{A} \beta$ fibril formation [94]. Nevertheless, ellagic acid reduces significantly $A \beta$ induced neurotoxicity in human SH-SY5Y neuroblastoma cells. These results are in agreement with the hypothesis that $\mathrm{A} \beta$ fibril formation may represent a protective mechanism of local $\mathrm{A} \beta$ clearance. Thus, ellagic acid may have therapeutic value in Alzheimer's disease.

3.2.3. Resveratrol and Other Stilbenes. Stilbenes are secondary metabolites described as phytoalexins. Stilbenes are found in grape vine and wine [95-97]. The main characteristic of stilbenes consist of diary groups on either end of an active double bond that generates the stilbene skeleton, the so-called resveratrol. Stilbenes can also be found in oligomeric and polymeric forms in wine [98]. Resveratrol is found in wine from trace amounts up to $10 \mathrm{mg} / \mathrm{L}$ typically $0.1 \mathrm{mg} / \mathrm{L}$ in white wines and $2.0 \mathrm{mg} / \mathrm{L}$ in red wines $[15,99]$. It is a substance with great potential that is being investigated intensively, and its derivatives exhibit a wide range of pharmacological and biological properties [100].

Resveratrol and its derivatives have also been reported to be active against neuron cell dysfunction and death in animal models [20, 101-104]. Resveratrol can cross the blood-brain barrier and exhibit neuroprotective properties against cerebral injury [105]. Numerous mechanisms may underline resveratrol neuroprotective effects against $A \beta$ induced neurotoxicity [106]. Resveratrol can act by reducing the intracellular $A \beta$ level by inducing protease degradation of the peptide in Alzheimer's disease. Resveratrol and other stilbenes have been shown to inhibit $A \beta$ fibril formation in vitro [107, 108]. Furthermore, resveratrol has been shown to exhibit significant free-radical scavenging abilities in numerous cellular models [109-112]. Thus, overall scientific data tend to show that among stilbenoids resveratrol has effects against brain injuries in reducing brain damage in complex manner including antioxidant properties, regulation on neurovascular system, or ability to inhibit known neuropathological processes.

\section{Mechanisms}

4.1. Bioavailability of Wine-Related Polyphenol. It is now well established that wine polyphenols exhibit some beneficial activities on health, particularly on neurodegenerative diseases [113]. Biological activities are often measured on cultured cells or isolated tissues using polyphenols in their form present in wine (as aglycone or their sugar derivatives). However, the question of their achievable concentration after ingestion as well as the possibility of conjugate formation has been ignored by many studies [114]. These data are though crucial for understanding polyphenol bioactivity. Several studies indicate that the antioxidant effect in vitro of some polyphenols may not indicate its activity in vivo. Indeed, its alteration into metabolites and other derivative constituents constitute the true bioactive molecules [113, 115-118]. Polyphenols are extensively metabolized in different tissues such as colon, small intestine, and liver [119]. Polyphenols are absorbed through the gut barrier. Some of them who are not absorbed pass to the large intestine and undergo colonic biotransformation by the enzymes of the colonic microflora [118]. Polyphenols metabolized in the gastrointestinal tract undergo conjugation in the liver after absorption. Then, polyphenols are present in circulation as sulfated, glucuronidated, methylated, and as mixed forms. Moreover, a large proportion of polyphenols ingested are subjected to hydrolyses and degradation by colonic microflora to simple phenolic compounds. Wine polyphenols are grouped into two categories: flavonoids and nonflavonoids as described before. Chemical structure of polyphenol is a factor involved in the gut absorption and the metabolism. We report here data on the absorption and the metabolism of the main polyphenols found in wine.

Concerning flavonoids, flavanols were absorbed and eliminated at low micromolar amounts of their direct conjugates (methylated, sulfated, and glucuronidated derivatives) [120]. However, the degradation of flavan structure in colon leads to the formation of phenolic compounds [114, 121]. Because of their hydrosolubility and high molecular weight, proanthocyanidins are not absorbed in the gut. The large majority of proanthocyanidins cross without alteration through the small intestine after which they are transformed by the colonic microflora to produce simple phenolic acids such as phenylacetic and phenylpropionic derivatives [122]. However, Tsang et al. reported that administration of grapeseed procyanidins induce the formation of catechin glucuronide derivatives in rat plasma [123]. Flavonols are naturally occurred as glycosides. Results indicate that flavonols uptake induce a cleavage of the glycoside part in the small intestine followed by absorption and metabolism of the aglycone [124]. Aglycones are then conjugated by sulfation and glucuronidation as well as methylation of the catechol group [118]. A large number of colonic metabolites identified are simple phenolic acids [125]. Anthocyanins was absorbed and excreted at a low proportion of the intact glycosides after injection of wine extract $[126,127]$. The anthocyanins degradation at the $\mathrm{pH}$ of the intestine in addition to the microflora activity in the colon are at least in part involved in the degradation of anthocyanins into more stable compound such as phenolic acids [113].

Concerning nonflavonoids, ellagitannins are not absorbed due to their large molecular size [128]. They are principally hydrolysed to ellagic acid under physiological conditions in small intestine [113]. Ellagic acid and ellagitannins reach the distal part of the small intestine and the colon, they are mainly transformated by gut microflora into urolithin derivatives [129]. The major stilbene compound found in wine is resveratrol; thus, bioavailability of resveratrol was investigated. Many investigations in animal models and humans have indicated that a low bioavailability of 
unconjugated resveratrol. More than $70 \%$ of the resveratrol uptaked is absorbed and readily transformed to produce essentially sulphate and glucuronide derivatives [99].

The conjugation of polyphenols has been recognized for many years, most of the biological studies have only been carried with polyphenol aglycones, and very little is known about the biological properties of conjugated derivatives. Numerous studies indicate that metabolic transformations of phenolic compounds reduce their antioxidant properties leading to less active antioxidants than the original compounds [130-132]. The formation of conjugated polyphenols and degradation products such as simple phenolic compounds will modify the properties observed in vivo in comparison to their unconjugated forms [114]. Much research effort is still needed to evaluate the biological effects of the conjugated derivatives and microbial metabolites of wine polyphenols.

4.2. Neurodegenerative Disorders and Oxidative Stress. Reactive oxygen species (ROS) are generated in living organisms due to various metabolic processes [108]. The narrow definition of ROS refers to oxygen free radicals, including superoxide radical anion, hydroxyl radical, hydroperoxyl radical and nonfree radicals, which can induce the generation of free radicals through divers chemical reactions. ROS produced in the human body can cause oxidative damage. Under oxidative stress, the excessive production of ROS may directly damage proteins, lipids, carbohydrates, DNA, and even cellular molecules involved in antioxidant defense systems. The over production of free radicals is implied in the progress of numerous diseases such as cardiovascular diseases, cancer, and neurodegenerative disorders [133-137]. To control, the levels of free radicals various defense mechanisms have been promoted in living organisms such as endogenous enzymes glutathione peroxidase, catalase, or superoxide dismutase. In addition to these endogenous mechanisms, much attention has been focused on the antioxidant role of some dietary compounds like polyphenols [27, 138, 139].

4.3. Antioxidants and Neuroprotection. The brain is characterized by its high susceptibility to oxidative stress due to its high oxygen consumption, its high fatty acids levels, and low antioxidant enzyme levels. Numerous works in the literature indicate that wine related-phenolic compounds exhibit a positive effect on nerve cells $[18,19,80]$. The mechanism proposed as explaining the effect on wine polyphenolic compounds on health can be principally summarized as scavenging intracellular ROS and inhibition of LDL oxidation $[110,140-142]$. In recent years, studies on the activity of wine polyphenols have been extended to animal models of CNS disorders and injury [18, 143]. These effects are principally associated to their strong antioxidant capacities, since they can act as free-radical scavengers and hydrogen or electron, to preventing DNA damage and lipid peroxidation $[144,145]$. Antioxidant polyphenols protect cell constituents from oxidative alteration and thus limit the risk of developing degenerative disorders induced by oxidative stress, such as in ischemia, Parkinson's disease or Alzheimer's disease. For example, an increasing number of reports has shown that acute chronic treatment of resveratrol exhibits neuroprotective effects against colchicine andnitropropionic acid [146] or motor impairment as well as hippocampal neuron loss $[147,148]$. These properties are mainly associated to the antioxidant activity of resveratrol. Resveratrol decreases the oxidative damages, in reducing the levels of malondialdehyde, lipid peroxidation, xanthine oxidase, and nitric oxide, and in increasing the depleted glutathione levels and succinate dehydrogenase activity in rat brain [149, 150].

4.4. Effect of Wine Polyphenols on Redox Imbalance. In the living organism, free radicals are generated both enzymatically and nonenzymatically, inducing the generation of reactive oxygen species, which have a crucial role in neurodegenerative disorders. Thus, in neurodegenerative pathologies and aging, the neuronal cells of specific brain regions may be exposed to ROS attack, and apoptotic cell death occurs and progressively worsens until malfunctioning of the neural network and manifestations of neurodegenerative disorders ensue [151].

Compelling evidence supports that oxidative stress plays key role in the physiopathology of neurodegenerative disorders. ROS level augmentation induces oxidation of cellular components leading to a neurodegenerative signaling cascade, which generates cellular damages and induces cell death [152-155]. To prevent oxidative damage, mammalian cells have developed a complex antioxidant defense system converting ROS to less harmful species [156, 157]. Thus, a potential approach in the treatment of neurodegenerative disorders is the use of antioxidants. They have the capacity to scavenge ROS and to upmodulate endogenous antioxidant defenses. In brain, such compounds should have the capacity to cross the blood-brain barrier.

In cells, oxidative stress is associated to sugar, lipid, DNA, and protein damages. The imbalance between antioxidant defense mechanisms and the intracellular production of free radicals induces oxidative stress [158]. Neurons in their ability to regulate for redox imbalance have an age-related decrease, even minor cellular stresses can lead to irreversible disorders and, as such, participate to the causes of neurodegenerative pathologies [158]. The accumulation of free radicals may activate $\beta$-secretase, resulting in formation of $\beta$ amyloid, which is believed to be responsible for synaptic dysfunction and neuronal cell death in Alzheimer's disease [159, 160]. The wine polyphenols are powerful anti-oxidants that inhibit the production of free radicals $[161,162]$, preventing cells from free radical and cellular DNA damages [163-165]. Indeed, the overproduction of reactive nitrogen and oxygen species by phagocytes induces oxidative damage to proteins, lipoproteins, and DNA. These reactions may be harmful to cells and tissues and lead to inflammation [166, 167]. Thus, to reduce many inflammatory disorders inhibition of reactive nitrogen and oxygen species production is a popular target. Wine related polyphenols with their antioxidative capacities may have therapeutic value in the prevention of oxidative stress [168, 169]. Furthermore, results indicate 
that polyphenols from wine have both the antioxidative and anti-inflammatory properties $[170,171]$ and that they can prevent cardiovascular diseases $[172,173]$. It is also thought that polyphenols act to modulate free radical-mediated lipid peroxidation of low-density lipoproteins (LDL), which is correlated to chronic diseases such as atherosclerosis [138, 174, 175].

4.5. Effect of Wine Polyphenols on NO Production. In complement to the antioxidant abilities of polyphenols, they might exert protective effects by improving endothelial function as indicated by both experimental and clinical studies [176]. As known for a long time, the endothelium have a crucial function in vascular health by regulating several vasorelaxing factors such as nitric oxide (NO) and endotheliumderived hyperpolarizing factor [177-180]. Indeed, the beneficial mechanisms of red wine polyphenolic compounds mainly involve the activation of endothelial NO, release through an increase in calcium levels and activation of the phosphoinositide-3 kinase/Akt pathway in endothelial cells $[178,179,181]$. Red wine polyphenolic compounds may also regulate NO activity at the level of endothelial nitric oxide synthase (eNOS) protein expression in endothelial cells [182] and blood vessels [183]. Chronic upregulation of eNOS by red wine polyphenolic compounds might constitute a preventive approach to reduce tissue injury associated with the risk of cerebral ischemia. For example, results indicate that resveratrol protects the spinal cord from ischemia-reperfusion injury by decreasing oxidative stress and increasing NO release. Resveratrol-induced neuroprotection is thus mediated by both antioxidant- and NOpromoting properties [184]. There is substantial evidence that polyphenols in red wine can exhibit anti-inflammatory abilities. This could be due to their capacities to scavenge NO or to decrease the NO synthase activity $[110,164,185]$. Resveratrol could also inhibit the neuronal NO synthase and the inducible NO synthase isoforms $[164,186]$. Therefore, resveratrol could induce the activity of vasodilator-inducing enzyme such as the endothelial isoform eNOS. This effect may be associated to the anti-inflammatory property of resveratrol [187]. Additionally, Han et al. indicated that resveratrol analogues exert neuroprotective effects by the activation of some receptor binding sites localized at the level of the cellular plasma membrane in rat brain [188]. The polyphenol binding to this specific receptor may induce nitric oxide synthase activity in the brain [189]. However, the polyphenol prolonged action could modulate the sensitivity and the tolerance of its receptor. Similarly, low and high doses of red wine polyphenolic compounds have, respectively, proand antiangiogenic properties on postischemic neovascularization in vivo. Finally, results indicate that resveratrol uptake, in association with a moderate intake of wine, induces an NO upregulation effect on human platelets [190]. In addition, wine related-polyphenols may exert other effects such as decrease LDL oxidation and increase HDL to generate [190-192]. This unique dual effect of red wine polyphenolic compounds offers important perspectives for the treatment and prevention of different diseases.
4.6. Other Potent Effects of Wine Polyphenols. Because oxidative and nitrosative stress have a crucial impact in the causes of neurodegenerative diseases such as Alzheimer's and Parkinson's diseases and because antioxidant activity is the most studied effect of wine polyphenols, this paper was mainly focused on oxidative damage to neuronal molecules. Nevertheless, studies have indicated that polyphenols could exert neuronal regulation at different levels such antiamyloidogenic effects, neuroprotection through modulation of neural mediators and enzymes, and interaction with signaling pathways.

Resveratrol has been identified as a potential antiaging agent and several studies have been realized on protective abilities of stilbenes (resveratrol derivatives) against aging and specific neurodegenerative disorders [19, 107, 115, 164]. The neuronal regulation of resveratrol derivatives molecules could be defined through a number of complex biological processes involving, as previously discussed upregulation of brain-redox imbalance, interactions with signaling pathways crucial in inducing neuronal function and survival, regulation on neurovascular system, and ability to inhibit known neuropathological processes. In APP695-transfected cell lines, resveratrol, could reduce the level of secreted $A \beta$ peptide without directly affecting any other components of the $\mathrm{A} \beta$ metabolism tested [193]. The decrease of the production of $A \beta$ peptide could be related to the increase of its degradation. Also, resveratrol did not promote the $A \beta$ peptide clearance by metalloendopeptidases. The treatment of cells with proteasome inhibitors reduced the $A \beta$ decrease induced by resveratrol. Thus, resveratrol could affect the proteasome involved in the degradation of the $\mathrm{A} \beta$ peptide. It has been shown that resveratrol could have beneficial effects on cognitive function mediated by regulation on neurovascular system. A higher microvascular density in association with the increase of cerebral blood flow might ameliorate performance by direct increase of glucose and oxygen supply in brain [194]. Furthermore, a recent study reports that resveratrol quickly enhances blood flow into the brain, followed by increased brain oxygenation which has been correlated to the increased memory capacity and improved cognition [195]. Studies revealed that resveratrol and its derivatives identified in wine such as piceid and $\varepsilon$-viniferin glucoside inhibited in vitro the $\mathrm{A} \beta$ fibrils formation [107, 108]. Examination of the inhibitory data for the stilbene monomers suggests specific structure-activity relationships [196]. $\mathcal{E}$-viniferin glucoside has been shown to inhibit fibrillization of $\mathrm{A} \beta$ peptide and to protect $\mathrm{PC} 12$ cells against $\mathrm{A} \beta$-induced toxicity [197]. These results together suggest that neuroprotective action of resveratrol could protect neurons against brain injuries in reducing brain damage in complex manner. In addition to resveratrol, various polyphenols present in wine protective effects against neurodegenerative diseases by regulation at different levels $[115,198,199]$.

\section{Conclusion}

Wine polyphenols appear to be potentially neuroprotective agents by their capacity to inhibit and/or modulate several 
neurodegenerative processes. Their neuroprotective effects in in vitro and in vivo models of neurodegenerative disorders have been documented, and our own findings suggest that their mechanism of action involves their antioxidant activity, principally as scavenging intracellular ROS and inhibition of LDL oxidation, and also their activating effect on endothelial and inhibitory action on both neuronal and inducible nitric oxide synthase activity and subsequent NO production. On the other hand, as indicated by Singh et al., it would be unwise to extrapolate these results to human without conducting proper clinical trials in patients suffering from irreversible and extensive neuronal loss [200].

\section{References}

[1] K. Ritchie and S. Lovestone, "The dementias," The Lancet, vol. 360, no. 9347, pp. 1759-1766, 2002.

[2] L. Esposito, J. Raber, L. Kekonius et al., "Reduction in mitochondrial superoxide dismutase modulates Alzheimer's disease-like pathology and accelerates the onset of behavioral changes in human amyloid precursor protein transgenic mice," Journal of Neuroscience, vol. 26, no. 19, pp. 5167-5179, 2006.

[3] D. E. Hu and K. M. Brindle, "Immune cell-induced synthesis of NO and reactive oxygen species in lymphoma cells causes their death by apoptosis," FEBS Letters, vol. 579, no. 13, pp. 2833-2841, 2005.

[4] R. G. Allen and M. Tresini, "Oxidative stress and gene regulation," Free Radical Biology and Medicine, vol. 28, no. 3, pp. 463-499, 2000.

[5] V. M. Victor, M. Rocha, and M. De La Fuente, "Immune cells: free radicals and antioxidants in sepsis," International Immunopharmacology, vol. 4, no. 3, pp. 327-347, 2004.

[6] H. Y. Chen and G. C. Yen, "Antioxidant activity and free radical-scavenging capacity of extracts from guava (Psidium guajava L.) leaves," Food Chemistry, vol. 101, no. 2, pp. 686694, 2007.

[7] L. Migliore and F. Coppedè, "Environmental-induced oxidative stress in neurodegenerative disorders and aging," Mutation Research, vol. 674, no. 1-2, pp. 73-84, 2009.

[8] E. Esposito, D. Rotilio, V. Di Matteo, C. Di Giulio, M. Cacchio, and S. Algeri, "A review of specific dietary antioxidants and the effects on biochemical mechanisms related to neurodegenerative processes," Neurobiology of Aging, vol. 23, no. 5, pp. 719-735, 2002.

[9] N. Hogg and B. Kalyanaraman, "Nitric oxide and lipid peroxidation," Biochimica et Biophysica Acta, vol. 1411, no. 2-3, pp. 378-384, 1999.

[10] V. Di Matteo and E. Esposito, "Biochemical and therapeutic effects of antioxidants in the treatment of Alzheimer's disease, Parkinson's disease, and amyotrophic lateral sclerosis," Curr Drug Target CNS Neurol Disord, vol. 2, no. 2, pp. 95-107, 2003.

[11] P. M. Kris-Etherton, K. D. Hecker, A. Bonanome et al., "Bioactive compounds in foods: their role in the prevention of cardiovascular disease and cancer," American Journal of Medicine, vol. 113, no. 9, 2002.

[12] M. C. De Rijk, M. M. B. Breteler, J. H. Den Breeijen et al., "Dietary antioxidants and Parkinson disease: the Rotterdam Study," Archives of Neurology, vol. 54, no. 6, pp. 762-765, 1997.

[13] J.-F. Dartigues, L. Letenneur, P. Joly, C. Helmer, J.-M. Orgogozo, and D. Commenges, "Age specific risk of dementia according to gender, education and wine consumption," Neurobiology of Aging, vol. 21, p. 64, 2000.

[14] J. M. Orgogozo, J. F. Dartigues, S. Lafont et al., "Wine consumption and dementia in the elderly: a prospective community study in the Bordeaux area," Revue Neurologique, vol. 153, no. 3, pp. 185-192, 1997.

[15] A. L. Waterhouse, "Wine phenolics," Annals of the New York Academy of Sciences, vol. 957, pp. 21-36, 2002.

[16] F. Aboul-ela, J. Karn, and G. Varani, "The structure of the human immunodeficiency virus type-1 TAR RNA reveals principles of RNA recognition by Tat protein," Journal of Molecular Biology, vol. 253, no. 2, pp. 313-332, 1995.

[17] A. Y. Sun, A. Simonyi, and G. Y. Sun, "The "French paradox" and beyond: neuroprotective effects of polyphenols," Free Radical Biology and Medicine, vol. 32, no. 4, pp. 314-318, 2002.

[18] M. Assunção, M. J. Santos-Marques, V. de Freitas et al., "Red wine antioxidants protect hippocampal neurons against ethanol-induced damage: a biochemical, morphological and behavioral study," Neuroscience, vol. 146, no. 4, pp. 15811592, 2007.

[19] S. Bastianetto, "Red wine consumption and brain aging," Nutrition, vol. 18, no. 5, pp. 432-433, 2002.

[20] C. Ramassamy, "Emerging role of polyphenolic compounds in the treatment of neurodegenerative diseases: a review of their intracellular targets," European Journal of Pharmacology, vol. 545, no. 1, pp. 51-64, 2006.

[21] D.-Y. Choi, Y.-J. Lee, J. T. Hong, and H.-J. Lee, “Antioxidant properties of natural polyphenols and their therapeutic potentials for Alzheimer's disease," Brain Research Bulletin, vol. 87, no. 2-3, pp. 144-153, 2012.

[22] J. Bruneton, "Part 2: Phenolic compounds," in Pharmacognosie, E. T. Doc, Ed., p. 259, Lavoisier, Paris, France, 2009.

[23] E. Haslam, Plant Polyphenols, Cambridge University Press, Cambridge, UK, 1989.

[24] E. Haslam, Practical Polyphenolics: From Structure to Molecular Recognition \& Physiological Action, Cambridge University Press, Cambridge, UK, 1998.

[25] E. N. Frankel, A. L. Waterhouse, and P. L. Teissedre, "Principal phenolic phytochemicals in selected California wines and their antioxidant activity in inhibiting oxidation of human low-density lipoproteins," Journal of Agricultural and Food Chemistry, vol. 43, no. 4, pp. 890-894, 1995.

[26] C. A. Rice-Evans and N. J. Miller, "Antioxidant activities of flavonoids as bioactive components of food," Biochemical Society Transactions, vol. 24, no. 3, pp. 790-795, 1996.

[27] C. A. Rice-Evans, N. J. Miller, and G. Paganga, "Antioxidant properties of phenolic compounds," Trends in Plant Science, vol. 2, no. 4, pp. 152-159, 1997.

[28] S. I. Koo and S. K. Noh, "Green tea as inhibitor of the intestinal absorption of lipids: potential mechanism for its lipid-lowering effect," Journal of Nutritional Biochemistry, vol. 18, no. 3, pp. 179-183, 2007.

[29] D. Wu, Z. Guo, Z. Ren, W. Guo, and S. N. Meydani, "Green tea EGCG suppresses T cell proliferation through impairment of IL-2/IL-2 receptor signaling," Free Radical Biology and Medicine, vol. 47, no. 5, pp. 636-643, 2009.

[30] I. C. W. Arts, B. Van De Putte, and P. C. H. Hollman, "Catechin contents of foods commonly consumed in The Netherlands. 2. Tea, wine, fruit juices, and chocolate milk," Journal of Agricultural and Food Chemistry, vol. 48, no. 5, pp. 1752-1757, 2000. 
[31] S. Mandel and M. B. H. Youdim, "Catechin polyphenols: neurodegeneration and neuroprotection in neurodegenerative diseases," Free Radical Biology and Medicine, vol. 37, no. 3, pp. 304-317, 2004.

[32] B. A. Sutherland, R. M. A. Rahman, and I. Appleton, "Mechanisms of action of green tea catechins, with a focus on ischemia-induced neurodegeneration," Journal of Nutritional Biochemistry, vol. 17, no. 5, pp. 291-306, 2006.

[33] S. Mandel, T. Amit, L. Reznichenko, O. Weinreb, and M. B. H. Youdim, "Green tea catechins as brain-permeable, natural iron chelators-antioxidants for the treatment of neurodegenerative disorders," Molecular Nutrition and Food Research, vol. 50, no. 2, pp. 229-234, 2006.

[34] A. Faria, D. Pestana, D. Teixeira et al., "Insights into the putative catechin and epicatechin transport across bloodbrain barrier," Food and Function, vol. 2, no. 1, pp. 39-44, 2011.

[35] D. Vauzour, G. Ravaioli, K. Vafeiadou, A. Rodriguez-Mateos, C. Angeloni, and J. P. E. Spencer, "Peroxynitrite induced formation of the neurotoxins 5-S-cysteinyl-dopamine and DHBT-1: implications for Parkinson's disease and protection by polyphenols," Archives of Biochemistry and Biophysics, vol. 476, no. 2, pp. 145-151, 2008.

[36] R. Li, Y. G. Huang, D. Fang, and W. D. Le, “(-)Epigallocatechin gallate inhibits lipopolysaccharide-induced microglial activation and protects against inflammationmediated dopaminergic neuronal injury," Journal of Neuroscience Research, vol. 78, no. 5, pp. 723-731, 2004.

[37] O. Weinreb, S. Mandel, T. Amit, and M. B. H. Youdim, "Neurological mechanisms of green tea polyphenols in Alzheimer's and Parkinson's diseases," Journal of Nutritional Biochemistry, vol. 15, no. 9, pp. 506-516, 2004.

[38] Y. T. Choi, C. H. Jung, S. R. Lee et al., “The green tea polyphenol (-)-epigallocatechin gallate attenuates $\beta$-amyloid-induced neurotoxicity in cultured hippocampal neurons," Life Sciences, vol. 70, no. 5, pp. 603-614, 2001.

[39] Y. Levites, T. Amit, M. B. H. Youdim, and S. Mandel, "Involvement of protein kinase C activation and cell survival/ cell cycle genes in green tea polyphenol (-)-epigallocatechin 3 -gallate neuroprotective action," The Journal of Biological Chemistry, vol. 277, no. 34, pp. 30574-30580, 2002.

[40] A. K. Patel, J. T. Rogers, and X. Huang, "Flavanols, mild cognitive impairment, and Alzheimer's dementia," International Journal of Clinical and Experimental Medicine, vol. 1, no. 2, pp. 181-191, 2008.

[41] C. Santos-Buelga and A. Scalbert, "Proanthocyanidins and tannin-like compounds-nature, occurrence, dietary intake and effects on nutrition and health," Journal of the Science of Food and Agriculture, vol. 80, no. 7, pp. 1094-1117, 2000.

[42] M. Sato, G. Maulik, P. S. Ray, D. Bagchi, and D. K. Das, "Cardioprotective effects of grape seed proanthocyanidin against ischemic reperfusion injury," Journal of Molecular and Cellular Cardiology, vol. 31, no. 6, pp. 1289-1297, 1999.

[43] G. Aldini, M. Carini, A. Piccoli, G. Rossoni, and R. M. Facino, "Procyanidins from grape seeds protect endothelial cells from peroxynitrite damage and enhance endotheliumdependent relaxation in human artery: new evidences for cardio-protection," Life Sciences, vol. 73, no. 22, pp. 28832898, 2003.

[44] K. Narita, M. Hisamoto, T. Okuda, and S. Takeda, "Differential neuroprotective activity of two different grape seed extracts," PLoS ONE, vol. 6, no. 1, Article ID e14575, 2011.

[45] T. Takahashi, T. Kamiya, A. Hasegawa, and Y. Yokoo, "Procyanidin oligomers selectively and intensively promote proliferation of mouse hair epithelial cells in vitro and activate hair follicle growth in vivo," Journal of Investigative Dermatology, vol. 112, no. 3, pp. 310-316, 1999.

[46] J. Deshane, L. Chaves, K. V. Sarikonda et al., "Proteomics analysis of rat brain protein modulations by grape seed extract," Journal of Agricultural and Food Chemistry, vol. 52, no. 26, pp. 7872-7883, 2004.

[47] V. L. Singleton, "Wine phenols," in Wine Analysis, H. F. Linskens and J. F. Jackson, Eds., p. 171, Springer, Berlin, Germany, 1988.

[48] D. P. Makris, S. Kallithraka, and P. Kefalas, "Flavonols in grapes, grape products and wines: burden, profile and influential parameters," Journal of Food Composition and Analysis, vol. 19, no. 5, pp. 396-404, 2006.

[49] J. Burns, P. T. Gardner, D. Matthews, G. G. Duthie, M. E. J. Lean, and A. Crozier, "Extraction of phenolics and changes in antioxidant activity of red wines during vinification," Journal of Agricultural and Food Chemistry, vol. 49, no. 12, pp. 57975808, 2001.

[50] K. A. Youdim, M. Z. Qaiser, D. J. Begley, C. A. Rice-Evans, and N. J. Abbott, "Flavonoid permeability across an in situ model of the blood-brain barrier," Free Radical Biology and Medicine, vol. 36, no. 5, pp. 592-604, 2004.

[51] K. A. Youdim, B. Shukitt-Hale, and J. A. Joseph, "Flavonoids and the brain: interactions at the blood-brain barrier and their physiological effects on the central nervous system," Free Radical Biology and Medicine, vol. 37, no. 11, pp. 16831693, 2004.

[52] J. H. Ho and Y. L. Chang, "Protective effects of quercetin and vitamin $\mathrm{C}$ against oxidative stress-induced neurodegeneration," Journal of Agricultural and Food Chemistry, vol. 52, no. 25, pp. 7514-7517, 2004.

[53] A. K. Samhan-Arias, F. J. Martín-Romero, and C. GutiérrezMerino, "Kaempferol blocks oxidative stress in cerebellar granule cells and reveals a key role for reactive oxygen species production at the plasma membrane in the commitment to apoptosis," Free Radical Biology and Medicine, vol. 37, no. 1, pp. 48-61, 2004.

[54] M. A. Ansari, H. M. Abdul, G. Joshi, W. O. Opii, and D. A. Butterfield, "Protective effect of quercetin in primary neurons against $\mathrm{A} \beta(1-42)$ : relevance to Alzheimer's disease," Journal of Nutritional Biochemistry, vol. 20, no. 4, pp. 269275, 2009.

[55] A. K. Pandey, P. P. Hazari, R. Patnaik, and A. K. Mishra, "The role of ASICla in neuroprotection elicited by quercetin in focal cerebral ischemia," Brain Research, vol. 1383, pp. 289299, 2011.

[56] E. M. Francia-Aricha, M. T. Guerra, J. C. Rivas-Gonzalo, and C. Santos-Buelga, "New anthocyanin pigments formed after condensation with flavanols," Journal of Agricultural and Food Chemistry, vol. 45, no. 6, pp. 2262-2266, 1997.

[57] V. De Freitas, C. Sousa, A. M. S. Silva, C. Santos-Buelga, and N. Mateus, "Synthesis of a new catechin-pyrylium derived pigment," Tetrahedron Letters, vol. 45, no. 51, pp. 9349-9352, 2004.

[58] H. Fulcrand, A. Cheminat, R. Brouillard, and V. Cheynier, "Characterization of compounds obtained by chemical oxidation of caffeic acid in acidic conditions," Phytochemistry, vol. 35, no. 2, pp. 499-505, 1994.

[59] M. D. Rivero-Pérez, P. Muñiz, and M. L. González-Sanjosé, "Contribution of anthocyanin fraction to the antioxidant properties of wine," Food and Chemical Toxicology, vol. 46, no. 8, pp. 2815-2822, 2008. 
[60] J. M. Kong, L. S. Chia, N. K. Goh, T. F. Chia, and R. Brouillard, "Analysis and biological activities of anthocyanins," Phytochemistry, vol. 64, no. 5, pp. 923-933, 2003.

[61] S. Zafra-Stone, T. Yasmin, M. Bagchi, A. Chatterjee, J. A. Vinson, and D. Bagchi, "Berry anthocyanins as novel antioxidants in human health and disease prevention," Molecular Nutrition and Food Research, vol. 51, no. 6, pp. 675-683, 2007.

[62] A. Castañeda-Ovando, M. D. L. Pacheco-Hernandez Ma.d.L., M. E. Páez-Hernández, J. A. Rodríguez, and C. A. GalánVidal, "Chemical studies of anthocyanins: a review," Food Chemistry, vol. 113, no. 4, pp. 859-871, 2009.

[63] D. Ghosh and T. Konishi, "Anthocyanins and anthocyaninrich extracts: role in diabetes and eye function," Asia Pacific Journal of Clinical Nutrition, vol. 16, no. 2, pp. 200-208, 2007.

[64] A. Karlsen, L. Retterstøl, P. Laake et al., "Anthocyanins inhibit nuclear factor- $\kappa \mathrm{B}$ activation in monocytes and reduce plasma concentrations of pro-inflammatory mediators in healthy adults," Journal of Nutrition, vol. 137, no. 8, pp. 1951-1954, 2007.

[65] R. Sasaki, N. Nishimura, H. Hoshino et al., "Cyanidin 3glucoside ameliorates hyperglycemia and insulin sensitivity due to downregulation of retinol binding protein 4 expression in diabetic mice," Biochemical Pharmacology, vol. 74, no. 11, pp. 1619-1627, 2007.

[66] M. C. Toufektsian, M. De Lorgeril, N. Nagy et al., "Chronic dietary intake of plant-derived anthocyanins protects the rat heart against ischemia-reperfusion injury," Journal of Nutrition, vol. 138, no. 4, pp. 747-752, 2008.

[67] P. E. Milbury and W. Kalt, "Xenobiotic metabolism and berry flavonoid transport across the blood? brain barrier," Journal of Agricultural and Food Chemistry, vol. 58, no. 7, pp. 39503956, 2010.

[68] S. Talavéra, C. Felgines, O. Texier et al., "Anthocyanin metabolism in rats and their distribution to digestive area, kidney, and brain," Journal of Agricultural and Food Chemistry, vol. 53, no. 10, pp. 3902-3908, 2005.

[69] P. H. Shih, Y. C. Chan, J. W. Liao, M. F. Wang, and G. C. Yen, "Antioxidant and cognitive promotion effects of anthocyanin-rich mulberry (Morus atropurpurea L.) on senescence-accelerated mice and prevention of Alzheimer's disease," Journal of Nutritional Biochemistry, vol. 21, no. 7, pp. 598-605, 2010.

[70] M. A. Papandreou, A. Dimakopoulou, Z. I. Linardaki et al., "Effect of a polyphenol-rich wild blueberry extract on cognitive performance of mice, brain antioxidant markers and acetylcholinesterase activity," Behavioural Brain Research, vol. 198, no. 2, pp. 352-358, 2009.

[71] A. Tarozzi, F. Morroni, S. Hrelia et al., "Neuroprotective effects of anthocyanins and their in vivo metabolites in $\mathrm{SH}$ SY5Y cells," Neuroscience Letters, vol. 424, no. 1, pp. 36-40, 2007.

[72] M. G. Varadinova, D. I. Docheva-Drenska, and N. I. Boyadjieva, "Effects of anthocyanins on learning and memory of ovariectomized rats," Menopause, vol. 16, no. 2, pp. 345-349, 2009.

[73] R. Acquaviva, A. Russo, F. Galvano et al., "Cyanidin and cyanidin 3-O- $\beta$-D-glucoside as DNA cleavage protectors and antioxidants," Cell Biology and Toxicology, vol. 19, no. 4, pp. 243-252, 2003.

[74] C. Di Giacomo, R. Acquaviva, A. Piva et al., "Protective effect of cyanidin 3-O- $\beta$-d-glucoside on ochratoxin A-mediated damage in the rat," British Journal of Nutrition, vol. 98, no. 5, pp. 937-943, 2007.
[75] U. Vrhovšek, "Extraction of hydroxycinnamoyltartaric acids from berries of different grape varieties," Journal of Agricultural and Food Chemistry, vol. 46, no. 10, pp. 4203-4208, 1998.

[76] M. Nardini, M. D’Aquino, G. Tomassi, V. Gentili, M. Di Felice, and C. Scaccini, "Inhibition of human low-density lipoprotein oxidation by caffeic acid and other hydroxycinnamic acid derivatives," Free Radical Biology and Medicine, vol. 19, no. 5, pp. 541-552, 1995.

[77] D. K. Maurya and T. P. A. Devasagayam, "Antioxidant and prooxidant nature of hydroxycinnamic acid derivatives ferulic and caffeic acids," Food and Chemical Toxicology, vol. 48, no. 12, pp. 3369-3373, 2010.

[78] D. Vauzour, G. Corona, and J. P. E. Spencer, "Caffeic acid, tyrosol and p-coumaric acid are potent inhibitors of 5-Scysteinyl-dopamine induced neurotoxicity," Archives of Biochemistry and Biophysics, vol. 501, no. 1, pp. 106-111, 2010.

[79] D. Sul, H. S. Kim, D. Lee, S. S. Joo, K. W. Hwang, and S. Y. Park, "Protective effect of caffeic acid against beta-amyloidinduced neurotoxicity by the inhibition of calcium influx and tau phosphorylation," Life Sciences, vol. 84, no. 9-10, pp. 257262, 2009.

[80] D. Vauzour, K. Vafeiadou, and J. P. E. Spencer, "Inhibition of the formation of the neurotoxin 5-S-cysteinyl-dopamine by polyphenols," Biochemical and Biophysical Research Communications, vol. 362, no. 2, pp. 340-346, 2007.

[81] R. Sultana, "Ferulic acid ethyl ester as a potential therapy in neurodegenerative disorders," Biochimica et Biophysica Acta, vol. 1822, no. 5, pp. 748-752, 2012.

[82] J. Kanski, M. Aksenova, A. Stoyanova, and D. A. Butterfield, "Ferulic acid antioxidant protection against hydroxyl and peroxyl radical oxidation in synaptosomal and neuronal cell culture systems in vitro: structure-activity studies," Journal of Nutritional Biochemistry, vol. 13, no. 5, pp. 273-281, 2002.

[83] C. M. Spencer, Y. Cai, R. Martin et al., "Polyphenol complexation-some thoughts and observations," Phytochemistry, vol. 27, no. 8, pp. 2397-2409, 1988.

[84] J. P. McManus, K. G. Davis, J. E. Beart, S. H. Gaffney, T. H. Lilley, and E. Haslam, "Polyphenol interactions. Part 1. Introduction; some observations on the reversible complexation of polyphenols with proteins and polysaccharides," Journal of the Chemical Society, no. 9, pp. 1429-1438, 1985.

[85] C. Adrian J, N. J. Baxter, T. H. Lilley, E. Haslam, C. J. McDonald, and M. P. Williamson, "Tannin interactions with a full-length human salivary proline-rich protein display a stronger affinity than with single proline-rich repeats," FEBS Letters, vol. 382, no. 3, pp. 289-292, 1996.

[86] N. Castillo-Munoz, S. Gomez-Alonso, E. Garcia-Romero, and I. Hermosan-Gutierrez, "Flavonol profiles of Vitis vinifera white grape cultivars," Journal of Food Composition and Analysis, vol. 23, no. 7, pp. 699-705, 2010.

[87] I. García-Estévez, M. T. Escribano-Bailón, J. C. RivasGonzalo, and C. Alcalde-Eon, "Development of a fractionation method for the detection and identification of oak ellagitannins in red wines," Analytica Chimica Acta, vol. 660, no. 1-2, pp. 171-176, 2010.

[88] M. K. Quinn and V. L. Singleton, "Isolation and identification of ellagitannins from white oak wood and an estimate of their roles in wine," American Journal of Enology and Viticulture, vol. 36, article 148, 1985.

[89] J. M. Landete, "Ellagitannins, ellagic acid and their derived metabolites: a review about source, metabolism, functions and health," Food Research International, vol. 44, no. 5, pp. 1150-1160, 2011. 
[90] S. Quideau, M. Jourdes, C. Saucier, Y. Glories, P. Pardon, and C. Baudry, "DNA topoisomerase inhibitor acutissimin a and other flavano-ellagitannins in red wine," Angewandte Chemie-International Edition, vol. 42, no. 48, pp. 6012 6014, 2003.

[91] T. Okuda, "Systematics and health effects of chemically distinct tannins in medicinal plants," Phytochemistry, vol. 66, no. 17, pp. 2012-2031, 2005.

[92] M. Larrosa, F. A. Tomás-Barberán, and J. C. Espín, "The dietary hydrolysable tannin punicalagin releases ellagic acid that induces apoptosis in human colon adenocarcinoma Caco-2 cells by using the mitochondrial pathway," Journal of Nutritional Biochemistry, vol. 17, no. 9, pp. 611-625, 2006.

[93] S. Quideau, D. Deffieux, C. Douat-Casassus, and L. Pouységu, "Plant polyphenols: chemical properties, biological activities, and synthesis," Angewandte Chemie-International Edition, vol. 50, no. 3, pp. 586-621, 2011.

[94] Y. Feng, S. G. Yang, X. T. Du et al., "Ellagic acid promotes A $\beta 42$ fibrillization and inhibits A $\beta 42$-induced neurotoxicity," Biochemical and Biophysical Research Communications, vol. 390, no. 4, pp. 1250-1254, 2009.

[95] R. Pezet, K. Gindro, O. Viret, and J. L. Spring, "Glycosylation and oxidative dimerization of resveratrol are respectively associated to sensitivity and resistance of grapevine cultivars to downy mildew," Physiological and Molecular Plant Pathology, vol. 65, no. 6, pp. 297-303, 2004.

[96] R. Pezet, V. Pont, and P. Cuenat, "Method to determine resveratrol and pterostilbene in grape berries and wines using high-performance liquid chromatography and highly sensitive fluorimetric detection," Journal of Chromatography A, vol. 663, pp. 191-197, 1994.

[97] R. Pezet, C. Perret, J. B. Jean-Denis, R. Tabacchi, K. Gindro, and $\mathrm{O}$. Viret, " $\delta$-viniferin, a resveratrol dehydrodimer: one of the major stilbenes synthesized by stressed grapevine leaves," Journal of Agricultural and Food Chemistry, vol. 51, no. 18, pp. 5488-5492, 2003.

[98] H. Amira-Guebailia, J. Valls, T. Richard et al., "Centrifugal partition chromatography followed by HPLC for the isolation of cis- $\varepsilon$-viniferin, a resveratrol dimer newly extracted from a red Algerian wine," Food Chemistry, vol. 113, no. 1, pp. 320-324, 2009.

[99] M. I. Fernández-Mar, R. Mateos, M. C. García-Parrilla, B. Puertas, and E. Cantos-Villar, "Bioactive compounds in wine: resveratrol, hydroxytyrosol and melatonin: a review," Food Chemistry, vol. 130, no. 4, pp. 797-813, 2012.

[100] O. Vang, N. Ahmad, C. A. Baile et al., "What is new for an old molecule? Systematic review and recommendations on the use of resveratrol," PLoS ONE, vol. 6, no. 6, Article ID e19881, 2011.

[101] T. S. Anekonda, "Resveratrol-A boon for treating Alzheimer's disease?" Brain Research Reviews, vol. 52, no. 2, pp. 316-326, 2006.

[102] Z. B. Gao, X. Q. Chen, and G. Y. Hu, "Inhibition of excitatory synaptic transmission by trans-resveratrol in rat hippocampus," Brain Research, vol. 1111, no. 1, pp. 41-47, 2006.

[103] S. A. Andrabi, M. G. Spina, P. Lorenz, U. Ebmeyer, G. Wolf, and T. F. W. Horn, "Oxyresveratrol (trans-2,3',4,5' tetrahydroxystilbene) is neuroprotective and inhibits the apoptotic cell death in transient cerebral ischemia," Brain Research, vol. 1017, no. 1-2, pp. 98-107, 2004.

[104] T. Richard, A. D. Pawlus, M. L. Iglésias et al., "Neuroprotective properties of resveratrol and derivatives," Annals of the New York Academy of Sciences, vol. 1215, no. 1, pp. 103-108, 2011.
[105] Q. Wang, J. Xu, G. E. Rottinghaus et al., "Resveratrol protects against global cerebral ischemic injury in gerbils," Brain Research, vol. 958, no. 2, pp. 439-447, 2002.

[106] M. Pallàs, G. Casadesús, M. A. Smith et al., "Resveratrol and neurodegenerative diseases: activation of SIRT1 as the potential pathway towards neuroprotection," Current Neurovascular Research, vol. 6, no. 1, pp. 70-81, 2009.

[107] C. Rivière, T. Richard, L. Quentin, S. Krisa, J. M. Mérillon, and J. P. Monti, "Inhibitory activity of stilbenes on Alzheimer's $\beta$-amyloid fibrils in vitro," Bioorganic and Medicinal Chemistry, vol. 15, no. 2, pp. 1160-1167, 2007.

[108] C. Rivière, Y. Papastamoulis, P. Y. Fortin et al., "New stilbene dimers against amyloid fibril formation," Bioorganic and Medicinal Chemistry Letters, vol. 20, no. 11, pp. 3441-3443, 2010.

[109] S. Chanvitayapongs, B. Draczynska-Lusiak, and A. Y. Sun, "Amelioration of oxidative stress by antioxidants and resveratrol in PC12 cells," NeuroReport, vol. 8, no. 6, pp. 1499-1502, 1997.

[110] S. Bastianetto and R. Quirion, "Natural extracts as possible protective agents of brain aging," Neurobiology of Aging, vol. 23, no. 5, pp. 891-897, 2002.

[111] J. Karlsson, M. Emgård, P. Brundin, and M. J. Burkitt, "transResveratrol protects embryonic mesencephalic cells from tert-butyl hydroperoxide: electron paramagnetic resonance spin trapping evidence for a radical scavenging mechanism," Journal of Neurochemistry, vol. 75, no. 1, pp. 141-150, 2000.

[112] K. Sinha, G. Chaudhary, and Y. Kumar Gupta, "Protective effect of resveratrol against oxidative stress in middle cerebral artery occlusion model of stroke in rats," Life Sciences, vol. 71, no. 6, pp. 655-665, 2002.

[113] J. C. Espín, M. T. García-Conesa, and F. A. Tomás-Barberán, "Nutraceuticals: facts and fiction," Phytochemistry, vol. 68, no. 22-24, pp. 2986-3008, 2007.

[114] A. R. Rechner, G. Kuhnle, P. Bremner, G. P. Hubbard, K. P. Moore, and C. A. Rice-Evans, "The metabolic fate of dietary polyphenols in humans," Free Radical Biology and Medicine, vol. 33, no. 2, pp. 220-235, 2002.

[115] A. Ebrahimi and H. Schluesener, "Natural polyphenols against neurodegenerative disorders: potentials and pitfalls," Ageing Research Reviews, vol. 11, no. 2, pp. 329-345, 2012.

[116] D. Del Rio, L. G. Costa, M. E. J. Lean, and A. Crozier, "Polyphenols and health: what compounds are involved?" Nutrition, Metabolism and Cardiovascular Diseases, vol. 20, no. 1, pp. 1-6, 2010.

[117] C. Manach, A. Scalbert, C. Morand, C. Rémésy, and L. Jiménez, "Polyphenols: food sources and bioavailability," The American Journal of Clinical Nutrition, vol. 79, no. 5, pp. 727747, 2004.

[118] A. Scalbert and G. Williamson, "Dietary intake and bioavailability of polyphenols," Journal of Nutrition, vol. 130, no. 8, pp. 2073S-2085S, 2000.

[119] C. Manach, G. Williamson, C. Morand, A. Scalbert, and C. Rémésy, "Bioavailability and bioefficacy of polyphenols in humans. I. Review of 97 bioavailability studies," The American Journal of Clinical Nutrition, vol. 81, no. 1, supplement, pp. 230S-242S, 2005.

[120] B. A. Warden, L. S. Smith, G. R. Beecher, D. A. Balentine, and B. A. Clevidence, "Catechins are bioavailable in men and women drinking black tea throughout the day," Journal of Nutrition, vol. 131, no. 6, pp. 1731-1737, 2001.

[121] C. Li, M. J. Lee, S. Sheng et al., "Structural identification of two metabolites of catechins and their kinetics in human 
urine and blood after tea ingestion," Chemical Research in Toxicology, vol. 13, no. 3, pp. 177-184, 2000.

[122] S. Déprez, C. Brezillon, S. Rabot et al., "Polymeric proanthocyanidins are catabolized by human colonic microflora into low-molecular-weight phenolic acids," Journal of Nutrition, vol. 130, no. 11, pp. 2733-2738, 2000.

[123] C. Tsang, C. Auger, W. Mullen et al., "The absorption, metabolism and excretion of flavan-3-ols and procyanidins following the ingestion of a grape seed extract by rats," British Journal of Nutrition, vol. 94, no. 2, pp. 170-181, 2005.

[124] P. C. Hollman and M. B. Katan, "Bioavailability and health effects of dietary flavonols in man," Archives of Toxicology, vol. 20, pp. 237-248, 1998.

[125] M. Gross, M. Pfeiffer, M. Martini, D. Campbell, J. Slavin, and J. Potter, "The quantitation of metabolites of quercetin flavonols in human urine," Cancer Epidemiology Biomarkers and Prevention, vol. 5, no. 9, pp. 711-720, 1996.

[126] T. Lapidot, S. Harel, R. Granit, and J. Kanner, "Bioavailability of red wine anthocyanins as detected in human urine," Journal of Agricultural and Food Chemistry, vol. 46, no. 10, pp. 4297-4302, 1998.

[127] M. Murkovic, H. Toplak, U. Adam, and W. Pfannhauser, "Analysis of anthocyanins in plasma for determination of their bioavailability," Journal of Food Composition and Analysis, vol. 13, no. 4, pp. 291-296, 2000.

[128] B. Cerdá, F. A. Tomás-Barberán, and J. C. Espín, "Metabolism of antioxidant and chemopreventive ellagitannins from strawberries, raspberries, walnuts, and oak-aged wine in humans: identification of biomarkers and individual variability," Journal of Agricultural and Food Chemistry, vol. 53, no. 2, pp. 227-235, 2005.

[129] B. Cerdá, P. Periago, J. C. Espín, and F. A. Tomás-Barberán, "Identification of urolithin A as a metabolite produced by human colon microflora from ellagic acid and related compounds," Journal of Agricultural and Food Chemistry, vol. 53, no. 14, pp. 5571-5576, 2005.

[130] Y. Miyake, K. Shimoi, S. Kumazawa, K. Yamamoto, N. Kinae, and T. Osawa, "Identification and antioxidant activity of flavonoid metabolites in plasma and urine of Eriocitrintreated rats," Journal of Agricultural and Food Chemistry, vol. 48, no. 8, pp. 3217-3224, 2000.

[131] M. Shirai, J. H. Moon, T. Tsushida, and J. Terao, "Inhibitory effect of a quercetin metabolite, quercetin 3-O- $\beta$ $\mathrm{D}$-glucuronide, on lipid peroxidation in liposomal membranes," Journal of Agricultural and Food Chemistry, vol. 49, no. 11, pp. 5602-5608, 2001.

[132] J. Terao, S. Yamaguchi, M. Shirai et al., "Protection by Quercetin and Quercetin 3-O- $\beta$-D-glucuronide of peroxynitrite-induced antioxidant consumption in human plasma low-density lipoprotein," Free Radical Research, vol. 35, no. 6, pp. 925-931, 2001.

[133] T. Dyrks, E. Dyrks, C. L. Masters, and K. Beyreuther, "Amyloidogenicity of rodent and human $\beta$ A4 sequences," FEBS Letters, vol. 324, no. 2, pp. 231-236, 1993.

[134] D. Dreher and A. F. Junod, "Role of oxygen free radicals in cancer development," European Journal of Cancer, vol. 32, no. 1, pp. 30-38, 1996.

[135] J. Galle, T. Hansen-Hagge, C. Wanner, and S. Seibold, "Impact of oxidized low density lipoprotein on vascular cells," Atherosclerosis, vol. 185, no. 2, pp. 219-226, 2006.

[136] D. Jay, H. Hitomi, and K. K. Griendling, "Oxidative stress and diabetic cardiovascular complications," Free Radical Biology and Medicine, vol. 40, no. 2, pp. 183-192, 2006.
[137] K. J. Barnham, C. L. Masters, and A. I. Bush, "Neurodegenerative diseases and oxidatives stress," Nature Reviews Drug Discovery, vol. 3, no. 3, pp. 205-214, 2004.

[138] I. Tedesco, M. Russo, P. Russo et al., "Antioxidant effect of red wine polyphenols on red blood cells," Journal of Nutritional Biochemistry, vol. 11, no. 2, pp. 114-119, 2000.

[139] S. B. Lotito and B. Frei, "Relevance of apple polyphenols as antioxidants in human plasma: contrasting in vitro and in vivo effects," Free Radical Biology and Medicine, vol. 36, no. 2, pp. 201-211, 2004.

[140] E. N. Frankel, A. L. Waterhouse, and J. E. Kinsella, "Inhibition of human LDL oxidation by resveratrol," The Lancet, vol. 341, no. 8852, pp. 1103-1104, 1993.

[141] J. H. Jang and Y. J. Surh, "Protective effect of resveratrol on $\beta$-amyloid-induced oxidative PC12 cell death," Free Radical Biology and Medicine, vol. 34, no. 8, pp. 1100-1110, 2003.

[142] Y. Miyagi, K. Miwa, and H. Inoue, "Inhibition of human lowdensity lipoprotein oxidation by flavonoids in red wine and grape juice," American Journal of Cardiology, vol. 80, no. 12, pp. 1627-1631, 1997.

[143] S. L. Chan, A. Tabellion, D. Bagrel, C. Perrin-Sarrado, C. Capdeville-Atkinson, and J. Atkinson, "Impact of chronic treatment with red wine polyphenols (RWP) on cerebral arterioles in the spontaneous hypertensive rat," Journal of Cardiovascular Pharmacology, vol. 51, no. 3, pp. 304-310, 2008.

[144] M. Fenech, C. Stockley, and C. Aitken, "Moderate wine consumption protects against hydrogen peroxide-induced DNA damage," Mutagenesis, vol. 12, no. 4, pp. 289-296, 1997.

[145] L. Giovannelli, G. Testa, C. De Filippo, V. Cheynier, M. N. Clifford, and P. Dolara, "Effect of complex polyphenols and tannins from red wine on DNA oxidative damage of rat colon mucosa in vivo," European Journal of Nutrition, vol. 39, no. 5, pp. 207-212, 2000.

[146] A. Kumar, P. S. Naidu, N. Seghal, and S. S. V. Padi, "Neuroprotective effects of resveratrol against intracerebroventricular colchicine-induced cognitive impairment and oxidative stress in rats," Pharmacology, vol. 79, no. 1, pp. 17-26, 2007.

[147] Ü. Sönmez, A. Sönmez, G. Erbil, I. Tekmen, and B. Baykara, "Neuroprotective effects of resveratrol against traumatic brain injury in immature rats," Neuroscience Letters, vol. 420, no. 2, pp. 133-137, 2007.

[148] H. Zhang, G. P. Schools, T. Lei, W. Wang, H. K. Kimelberg, and M. Zhou, "Resveratrol attenuates early pyramidal neuron excitability impairment and death in acute rat hippocampal slices caused by oxygen-glucose deprivation," Experimental Neurology, vol. 212, no. 1, pp. 44-52, 2008.

[149] O. Ates, S. Cayli, E. Altinoz et al., "Neuroprotection by resveratrol against traumatic brain injury in rats," Molecular and Cellular Biochemistry, vol. 294, no. 1-2, pp. 137-144, 2007.

[150] S. K. Tsai, L. M. Hung, Y. T. Fu et al., "Resveratrol neuroprotective effects during focal cerebral ischemia injury via nitric oxide mechanism in rats," Journal of Vascular Surgery, vol. 46, no. 2, pp. 346-353, 2007.

[151] A. Y. Sun and Y. M. Chen, "Oxidative stress and neurodegenerative disorders," Journal of Biomedical Science, vol. 5, no. 6, pp. 401-414, 1998.

[152] L. J. S. Greenlund, T. L. Deckwerth, and E. M. Johnson, "Superoxide dismutase delays neuronal apoptosis: a role for reactive oxygen species in programmed neuronal death," Neuron, vol. 14, no. 2, pp. 303-315, 1995.

[153] M. P. Mattson, R. J. Mark, K. Furukawa, and A. J. Bruce, "Distruption of brain cell ion homeostasis in Alzheimer's 
disease by oxy radicals, and signaling pathways that protect therefrom," Chemical Research in Toxicology, vol. 10, no. 5, pp. 507-517, 1997.

[154] M. B. Bogdanov, O. A. Andreassen, A. Dedeoglu, R. J. Ferrante, and M. F. Beal, "Increased oxidative damage to DNA in a transgenic mouse model of Huntington's disease," Journal of Neurochemistry, vol. 79, no. 6, pp. 1246-1249, 2001.

[155] M. Mokni, S. Elkahoui, F. Limam, M. Amri, and E. Aouani, "Effect of resveratrol on antioxidant enzyme activities in the brain of healthy rat," Neurochemical Research, vol. 32, no. 6, pp. 981-987, 2007.

[156] Z. Wu, L. J. Chen, and Y. J. Long, "Analysis of ultrastructure and reactive oxygen species of hyperhydric garlic (Allium sativum L.) shoots," In Vitro Cellular and Developmental Biology_Plant, vol. 45, no. 4, pp. 483-490, 2009.

[157] C. Fleury, B. Mignotte, and J. L. Vayssière, "Mitochondrial reactive oxygen species in cell death signaling," Biochimie, vol. 84, no. 2-3, pp. 131-141, 2002.

[158] G. Aliev, M. E. Obrenovich, V. P. Reddy et al., "Antioxidant therapy in Alzheimer's disease: theory and practice," Mini Reviews in Medicinal Chemistry, vol. 8, no. 13, pp. 1395-1406, 2008.

[159] R. Ehehalt, P. Keller, C. Haass, C. Thiele, and K. Simons, "Amyloidogenic processing of the Alzheimer $\beta$-amyloid precursor protein depends on lipid rafts," Journal of Cell Biology, vol. 160, no. 1, pp. 113-123, 2003.

[160] E. Tamagno, M. Guglielmotto, M. Aragno et al., "Oxidative stress activates a positive feedback between the $\gamma$ - and $\beta$ secretase cleavages of the $\beta$-amyloid precursor protein," Journal of Neurochemistry, vol. 104, no. 3, pp. 683-695, 2008.

[161] A. Ghiselli, M. Nardini, A. Baldi, and C. Scaccini, "Antioxidant activity of different phenolic fractions separated from an Italian red wine," Journal of Agricultural and Food Chemistry, vol. 46, no. 2, pp. 361-367, 1998.

[162] A. Kasdallah-Grissa, B. Mornagui, E. Aouani et al., "Resveratrol, a red wine polyphenol, attenuates ethanol-induced oxidative stress in rat liver," Life Sciences, vol. 80, no. 11, pp. 1033-1039, 2007.

[163] C. R. Pace-Asciak, S. Hahn, E. P. Diamandis, G. Soleas, and D. M. Goldberg, "The red wine phenolics trans-resveratrol and quercetin block human platelet aggregation and eicosanoid synthesis: implications for protection against coronary heart disease," Clinica Chimica Acta, vol. 235, no. 2, pp. 207-219, 1995.

[164] S. Bastianetto, W. H. Zheng, and R. Quirion, "Neuroprotective abilities of resveratrol and other red wine constituents against nitric oxide-related toxicity in cultured hippocampal neurons," British Journal of Pharmacology, vol. 131, no. 4, pp. 711-720, 2000.

[165] S. S. Leonard, C. Xia, B. H. Jiang et al., "Resveratrol scavenges reactive oxygen species and effects radical-induced cellular responses," Biochemical and Biophysical Research Communications, vol. 309, no. 4, pp. 1017-1026, 2003.

[166] D. Bagchi, M. Bagchi, S. J. Stohs et al., "Free radicals and grape seed proanthocyanidin extract: importance in human health and disease prevention," Toxicology, vol. 148, no. 2-3, pp. 187-197, 2000.

[167] L. J. Hofseth and M. J. Wargovich, "Inflammation, cancer, and targets of ginseng," Journal of Nutrition, vol. 137, no. 1, pp. 183S-185S, 2007.

[168] A. Ceriello, N. Bortolotti, E. Motz et al., "Red wine protects diabetic patients from meal-induced oxidative stress and thrombosis activation: a pleasant approach to the prevention of cardiovascular disease in diabetes," European Journal of Clinical Investigation, vol. 31, no. 4, pp. 322-328, 2001.

[169] R. Rodrigo, G. Rivera, M. Orellana, J. Araya, and C. Bosco, "Rat kidney antioxidant response to long-term exposure to flavonol rich red wine," Life Sciences, vol. 71, no. 24, pp. 28812895, 2002.

[170] L. E. Donnelly, R. Newton, G. E. Kennedy et al., "Antiinflammatory effects of resveratrol in lung epithelial cells: molecular mechanisms," American Journal of Physiology, vol. 287, no. 4, pp. L774-L783, 2004.

[171] A. R. Martín, I. Villegas, M. Sánchez-Hidalgo, and C. A. De La Lastra, "The effects of resveratrol, a phytoalexin derived from red wines, on chronic inflammation induced in an experimentally induced colitis model," British Journal of Pharmacology, vol. 147, no. 8, pp. 873-885, 2006.

[172] M. De Lorgeril, P. Salen, A. Guiraud, F. Boucher, and J. De Leiris, "Resveratrol and non-ethanolic components of wine in experimental cardiology," Nutrition, Metabolism and Cardiovascular Diseases, vol. 13, no. 2, pp. 100-103, 2003.

[173] A. Scalbert, C. Manach, C. Morand, C. Rémésy, and L. Jiménez, "Dietary polyphenols and the prevention of diseases," Critical Reviews in Food Science and Nutrition, vol. 45, no. 4, pp. 287-306, 2005.

[174] R. Stocker and R. A. O'Halloran, "Dealcoholized red wine decreases atherosclerosis in apolipoprotein E gene-deficient mice independently of inhibition of lipid peroxidation in the artery wall," The American Journal of Clinical Nutrition, vol. 79, no. 1, pp. 123-130, 2004.

[175] S. Gorelik, M. Ligumsky, R. Kohen, and J. Kanner, "A novel function of red wine polyphenols in humans: prevention of absorption of cytotoxic lipid peroxidation products," The FASEB Journal, vol. 22, no. 1, pp. 41-46, 2008.

[176] V. B. Schini-Kerth, C. Auger, J. H. Kim, N. EtienneSelloum, and T. Chataigneau, "Nutritional improvement of the endothelial control of vascular tone by polyphenols: role of NO and EDHF," Pflügers Archiv, vol. 459, no. 6, pp. 853$862,2010$.

[177] L. J. Ignarro, G. M. Buga, K. S. Wood, R. E. Byrns, and G. Chaudhuri, "Endothelium-derived relaxing factor produced and released from artery and vein is nitric oxide," Proceedings of the National Academy of Sciences of the United States of America, vol. 84, no. 24, pp. 9265-9269, 1987.

[178] M. H. Oak, M. Chataigneau, T. Keravis et al., "Red wine polyphenolic compounds inhibit vascular endothelial growth factor expression in vascular smooth muscle cells by preventing the activation of the p38 mitogen-activated protein kinase pathway," Arteriosclerosis, Thrombosis, and Vascular Biology, vol. 23, no. 6, pp. 1001-1007, 2003.

[179] G. E. Mann, D. J. Rowlands, F. Y. L. Li, P. de Winter, and R. C. M. Siow, "Activation of endothelial nitric oxide synthase by dietary isoflavones: role of $\mathrm{NO}$ in Nrf2-mediated antioxidant gene expression," Cardiovascular Research, vol. 75, no. 2, pp. 261-274, 2007.

[180] M. Feletou and P. M. Vanhoutte, "Endothelium-dependent hyperpolarization of canine coronary smooth muscle," British Journal of Pharmacology, vol. 93, no. 3, pp. 515-524, 1988.

[181] I. Bernátová, O. Pechánová, P. Babál, S. Kyselá, S. Stvrtina, and R. Andriantsitohaina, "Wine polyphenols improve cardiovascular remodeling and vascular function in NOdeficient hypertension," American Journal of Physiology, vol. 282, no. 3, pp. H942-H948, 2002.

[182] T. Wallerath, D. Poleo, H. Li, and U. Förstermann, "Red wine increases the expression of human endothelial nitric oxide 
synthase: a mechanism that may contribute to its beneficial cardiovascular effects," Journal of the American College of Cardiology, vol. 41, no. 3, pp. 471-478, 2003.

[183] M. Diebolt, B. Bucher, and R. Andriantsitohaina, "Wine polyphenols decrease blood pressure, improve NO vasodilatation, and induce gene expression," Hypertension, vol. 38, no. 2, pp. 159-165, 2001.

[184] U. Kiziltepe, N. N. D. Turan, U. Han, A. T. Ulus, and F. Akar, "Resveratrol, a red wine polyphenol, protects spinal cord from ischemia-reperfusion injury," Journal of Vascular Surgery, vol. 40, no. 1, pp. 138-145, 2004.

[185] C. Luceri, G. Caderni, A. Sanna, and P. Dolara, "Red wine and black tea polyphenols modulate the expression of cycloxygenase-2, inducible nitric oxide synthase and glutathionerelated enzymes in azoxymethane-induced F344 rat colon tumors," Journal of Nutrition, vol. 132, no. 6, pp. 1376-1379, 2002.

[186] L. M. Hung, M. J. Su, and J. K. Chen, "Resveratrol protects myocardial ischemia-reperfusion injury through both NOdependent and NO-independent mechanisms," Free Radical Biology and Medicine, vol. 36, no. 6, pp. 774-781, 2004.

[187] J. A. Baur, K. J. Pearson, N. L. Price et al., "Resveratrol improves health and survival of mice on a high-calorie diet," Nature, vol. 444, no. 7117, pp. 337-342, 2006.

[188] Y. S. Han, S. Bastianetto, Y. Dumont, and R. Quirion, "Specific plasma membrane binding sites for polyphenols, including resveratrol, in the rat brain," Journal of Pharmacology and Experimental Therapeutics, vol. 318, no. 1, pp. 238245, 2006.

[189] S. Bastianetto, J. Brouillette, and R. Quirion, "Neuroprotective effects of natural products: interaction with intracellular kinases, amyloid peptides and a possible role for transthyretin," Neurochemical Research, vol. 32, no. 10, pp. 1720-1725, 2007.

[190] P. Gresele, P. Pignatelli, G. Guglielmini et al., "Resveratrol, at concentrations attainable with moderate wine consumption, stimulates human platelet nitric oxide production," Journal of Nutrition, vol. 138, no. 9, pp. 1602-1608, 2008.

[191] A. Di Castelnuovo, S. Rotondo, L. Iacoviello, M. B. Donati, and G. De Gaetano, "Meta-analysis of wine and beer consumption in relation to vascular risk," Circulation, vol. 105, no. 24, pp. 2836-2844, 2002.

[192] C. Baron-Menguy, A. Bocquet, A. L. Guihot et al., "Effects of red wine polyphenols on postischemic neovascularization model in rats: low doses are proangiogenic, high doses antiangiogenic," The FASEB Journal, vol. 21, no. 13, pp. 35113521, 2007.

[193] P. Marambaud, H. Zhao, and P. Davies, "Resveratrol promotes clearance of Alzheimer's disease amyloid- $\beta$ peptides," The Journal of Biological Chemistry, vol. 280, no. 45, pp. 37377-37382, 2005.

[194] C. A. Oomen, E. Farkas, V. Roman, E. M. Van Der Beek, P. G. Luiten, P. Meerlo, and P. Meerlo, "Resveratrol preserves cerebrovascular density and cognitive function in aging mice," Frontiers in Aging Neuroscience, vol. 1, article 4, 2009.

[195] D. O. Kennedy, E. L. Wightman, J. L. Reay et al., "Effects of resveratrol on cerebral blood flow variables and cognitive performance in humans: a double-blind, placebo-controlled, crossover investigation," The American Journal of Clinical $\mathrm{Nu}$ trition, vol. 91, no. 6, pp. 1590-1597, 2010.

[196] C. Rivière, T. Richard, X. Vitrac, J. M. Mérillon, J. Valls, and J. P. Monti, "New polyphenols active on $\beta$-amyloid aggregation," Bioorganic and Medicinal Chemistry Letters, vol. 18, no. 2, pp. 828-831, 2008.
[197] T. Richard, P. Poupard, M. Nassra et al., "Protective effect of $\mathcal{E}$-viniferin on $\beta$-amyloid peptide aggregation investigated by electrospray ionization mass spectrometry," Bioorganic and Medicinal Chemistry, vol. 19, no. 10, pp. 3152-3155, 2011.

[198] K. Ono, L. Li, Y. Takamura et al., "Phenolic compounds prevent amyloid $\beta$-protein oligomerization and synaptic dysfunction by site-specific binding," The Journal of Biological Chemistry, vol. 278, pp. 14631-14643, 2012.

[199] J. P. E. Spencer, K. Vafeiadou, R. J. Williams, and D. Vauzour, "Neuroinflammation: modulation by flavonoids and mechanisms of action," Molecular Aspects of Medicine, vol. 33, no. 1, pp. 83-97, 2012.

[200] M. Singh, M. Arseneault, T. Sanderson, V. Murthy, and C. Ramassamy, "Challenges for research on polyphenols from foods in Alzheimer's disease: bioavailability, metabolism, and cellular and molecular mechanisms," Journal of Agricultural and Food Chemistry, vol. 56, no. 13, pp. 4855-4873, 2008. 


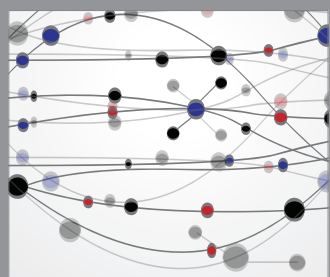

The Scientific World Journal
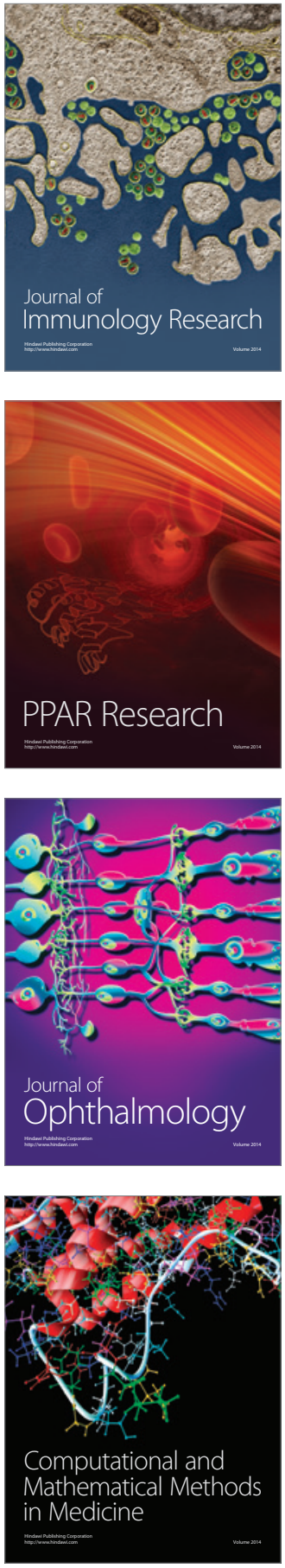

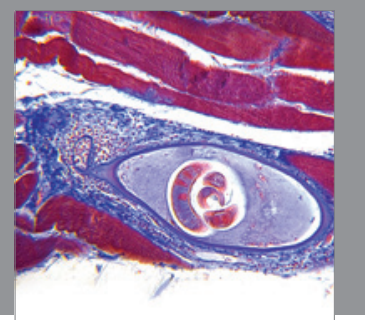

Gastroenterology

Research and Practice
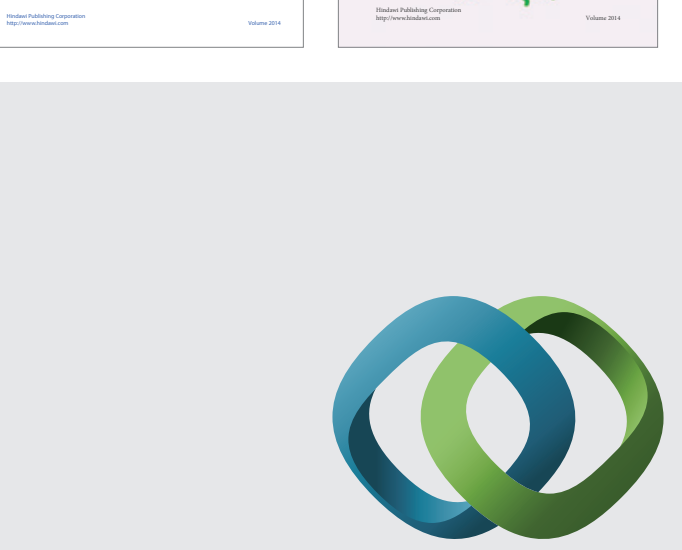

\section{Hindawi}

Submit your manuscripts at

http://www.hindawi.com
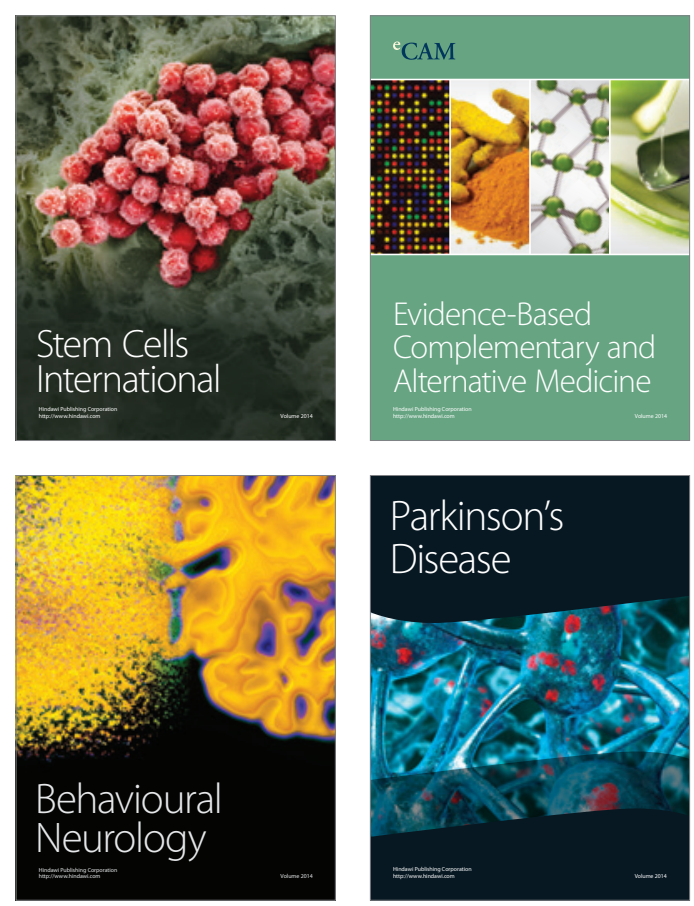

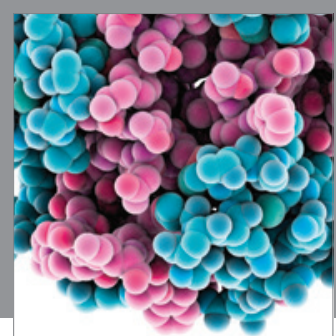

Journal of
Diabetes Research

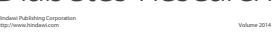

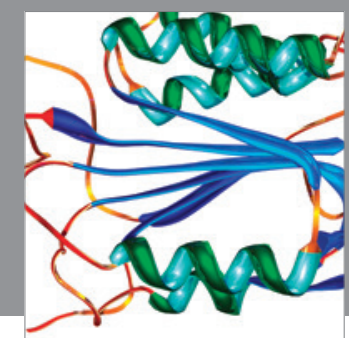

Disease Markers
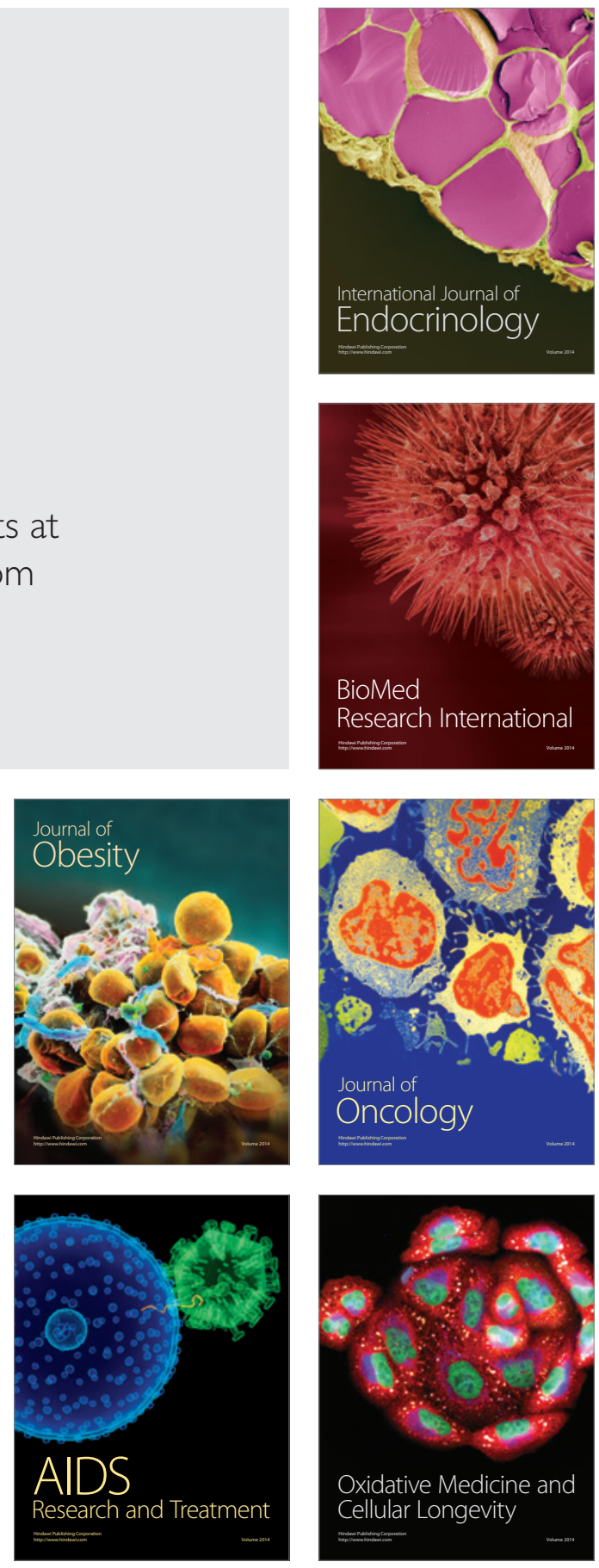